
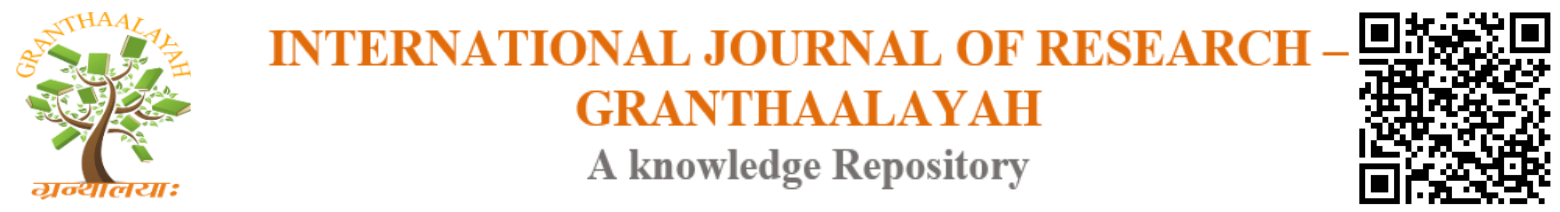

Social

\title{
THEORETICAL AND CONCEPTUAL FRAMEWORKS: AN INVESTIGATION ON THE HURDLES LEARNERS WITH VISUAL IMPAIRMENT FACE ACADEMICALLY DUE TO THE INTRODUCTION OF INCLUSIVE EDUCATION IN TWO SELECTED SECONDARY SCHOOLS IN ITEZHI-TEZHI DISTRICT OF ZAMBIA
}

\author{
Kapembwa Nthama ${ }^{1}$, Penda Annie ${ }^{2}$ \\ ${ }^{1,2}$ Kwame Nkrumah University P. O. Box 80404, Kabwe-Zambia
}

\begin{abstract}
This manuscript is an extract of a theoretical framework and conceptual framework from a Master's an on-going study on the hurdles learners with visual impairment face academically due to the introduction of inclusive education in two selected secondary schools in Itezhi-tezhi District of Zambia. The work is an attempt to identify the hardles affecting learners with visual impairment in Zambia. Among the factors that can affect these learners are such as attention, materials, financial support, trained teachers, and attitude. It is argued that if these factors are identified and addressed learners with visual impairment can benefit a lot from education under education system.
\end{abstract}

Keywords: Visual Impairment; Factors; Inclusive School; Hurdles; Secondary Schools; Academically.

Cite This Article: Kapembwa Nthama, and Penda Annie. (2019). "THEORETICAL AND CONCEPTUAL FRAMEWORKS: AN INVESTIGATION ON THE HURDLES LEARNERS WITH VISUAL IMPAIRMENT FACE ACADEMICALLY DUE TO THE INTRODUCTION OF INCLUSIVE EDUCATION IN TWO SELECTED SECONDARY SCHOOLS IN ITEZHITEZHI DISTRICT OF ZAMBIA.” International Journal of Research - Granthaalayah, 7(1), 396-404. https://doi.org/10.29121/granthaalayah.v7.i1.2019.1068.

\section{Introduction}

\subsection{Background}

Learners with visual impairment face a lot of difficulties in schools from the time inclusive education was introduced. This is supported by Korir (2015) who stated that learners with visual impairment do face a number of challenges for instance, the administrators viewing them as a burden to school and many times they do not meet their needs like providing to them the necessary learning materials even though they pay fees. 
At international level, learners with visual impairment have received a lot of support. For example in Brazil learners with visual impairment receive legal support towards their education as stated by Leandro et al (2018) that education is a right of individuals with visual impairment that must be secured at all educational levels in the country. Leandro and others noted the legal support that are given to learners with visual impairment in Brazil of which the researchers are in support, however the study did not bring to light the hurdles faced by learners with visual impairment in inclusive schools.

Learners with visual impairment who are in Africa do receive a variety of support. For instance, there is learning support provided to learners with visual impairment in Botswana (Habulezi and Phasia, 2012). The study by Habulezi and Phasia identified the support given to learners with visual impairment in Botswana which is learning support, although the study did not identify the hurdles faced by learners with visual impairment in inclusive schools.

In Zambia learners with visual impairment have been supported in terms of education by the government policy framework of 1996. For instance, Ministry of Education (1996) policy states that learners with disabilities are accorded equal chance to acquire education just like any other learner in the country. Furthermore in Zambian law, learners with special needs which include learners with visual impairment are supported legally by a legal framework of 2011. For example, the Education Act (2011) states that learners with disabilities should have equal access in terms of education from educational institutions. Although learners with visual impairment are supported in terms of policy and legal framework, the documents are silent on hurdles learners with visual impairment face academically in inclusive schools.

Though there is support in various ways at international level for instance in brazil then in Africa for instance in Botswana and Zambia there has been no much study done in term of identifying the hurdles learners with visual impairment face academically in inclusive schools. Therefore this study aim at investigating the hurdles learners with visual impairment face academically in inclusive schools in two selected secondary schools in Itezhi-tezhi district of Zambia.

\section{The Statement of the Problem}

Learners with visual impairment face a lot of difficulties in schools from the time inclusive education was introduced. Though there is support in various ways at international level for instance in brazil then in Africa for instance in Botswana and Zambia there has been no much study done in term of identifying the hurdles learners with visual impairment face academically in inclusive schools. Therefore this study is an investigation on the hurdles learners with visual impairment face academically in inclusive schools in two selected secondary schools in Itezhitezhi district.

\section{Purpose of the Study}

The main purpose of the ongoing study is to identify hurdles learners with visual impairment face academically due to the introduction of inclusive education. 


\subsection{The Research Objectives}

The ongoing study aim at achieving the following objectives;

1) The academic difficulties learners with visual impairment face in inclusive schools.

2) The views of learners with visual impairment on academic education they receive from inclusive schools.

3) Strategies that can be put in place to meet the academic needs of learners with visual impairment.

\subsection{Research Questions}

Below are the research questions which will help the researcher collect information on hurdles learners with visual impairment face academically in inclusive schools.

1) What hurdles learners with visual impairment face academically in inclusive schools?

2) What views do learners with visual impairment have on academic education they receive from inclusive schools?

3) What strategies can be put in place to meet the academic needs of learners with visual impairment?

\subsection{Significance of the Study}

The ongoing study is important because it might bring fourth the hurdles learners with visual impairment face academically in inclusive schools. It is also hoped that the findings of this study will be added to the board of knowledge on hurdles learners with visual impairment face academically in inclusive schools.

\subsection{Study Sites}

The ongoing research study will be conducted in two selected schools in Itezhi-tezhi district of Central Province in Zambia. The names of the schools include Uphill day secondary school and Itezhi-tezhi secondary school. These study sites were selected because they have learners with visual impairment and they are inclusive schools.

\subsection{Delimitation of the Study}

The research may be limited in scope due to the fact that it will only cover two selected secondary schools of Itezhi-tezhi district, making it difficult to generalize the results to other schools in Zambia.

\subsection{Theoretical Framework and Conceptual Framework}

The following theoretical framework and conceptual framework would be used while investigating on the hurdles learners with visual impairment face academically due to the introduction of inclusive education in two selected secondary schools in Itezhi-tezhi District of Zambia. 


\subsubsection{Theoretical Framework}

The ongoing study will be guided by social model of Oliver (2013). The model is based on the view that the disability problem is located outside the individual with disability. It looks beyond a person's impairment at all the relevant factors that affect their ability to be a full and equal participant in society. Oliver shows the need for disability to be addressed at every level and that everyday things should not be a barrier or even a special accommodation. People with disabilities have the right to enjoy the same childhood as their non-disabled siblings and friends such as to attend the local mainstream school, to use public services among others just as everyone else. In line with hurdles learners with visual impairment face, Olivers' social model contain the following aspects which includes; attitude, materials, trained teachers financial support and attention.

The subsequent paragraphs therefore, try to explain how involving attitude, materials, trained teachers and financial support can be used in identifying hurdles that affect learners with visual impairment in an inclusive school.

\section{Attitude}

The social model of disability focuses on people's attitudes towards disability and recognizes that attitudes towards disability can present barriers for disabled people in the same way the physical environment can (oliver, 2013). For instance, at a school level the attitudes that can be a barrier to a learner with visual impairment are; not involving learners with visual impairment in a lesson, for example learners may not give chance to ask questions. The other attitude is that of a teacher who may not prepare the work in braille for a learner with visual impairment especially for a learner who is totally blind. The teacher may also not prepare the work in large print for the learners who are partially sighted. Another attitude is that a teacher can prefer the learner with visual impairment to learn from fellow learners who are not visually impaired. Another form of attitude is where for example, the teacher may not use individual teaching when handling a learner with visual impairment believing that the learner with visual impairment will consume more time allocated for other learners who are not visually impaired. The teacher may also behave in such a way that the work for a pupil may not be evaluated for instance, the pupil's work may not be marked , checked and may not give extra work if the learner is not doing well.

The other attitude is where pupils may laugh at learners with visual impairment when they are answering or asking questions during academic exercises. Learners with visual impairment may be rejected during group work activities and sometime learners who are not visually impaired may not give helping hand to learners who are visually impaired especially when they move from one class to another. The pupils with sight may not even read for pupils with visual impairment if the teacher has given the work in printed materials. These are the attitudinal barriers that may come from the teachers and pupils toward learners with visual impairment and which can affect them academically.

\section{Materials}

Learners who are visually impaired in order to strengthen their academic learning, modified learning materials need to be provided to them and if not they face difficulties academically (Oliver, 2013). In a classroom situation if the learners who are totally blind are provided with ink print material they will face difficulties to access academic information, write classroom exercise, 
they will need to depend on others who are not visually impaired to read for them. In the case of learners who are partially sighted they may require large print and if not, they may face difficulties academically. In order to meet learners with visual impairment unique needs, learners must be provided with modified materials such as brailed books and other raised material such as raised maps, graphs and charts and large print materials as well as specialized equipment such as thermal form for printing braille material and Perkins bailer which is used for writing brailed material.

The learners will also need software technologies such as software synthesizer for the computer to enable the access of information from the computer. For example learners with visual impairment can use a screen reader such as Job Access With Speed (JAWS). Access to technology has enormous potential for supporting learners with visual impairment across different ages and abilities. In addition assistive technology, such as audio-visual devices or software, allows learners to work at their own pace and with the right training, often independently. For example, Technology to be a success, it requires the right device, training and time. When this is achieved, students can take control of part of their learning journey improving not only their academic progress, but also their self-confidence in learning sphere and the wider life. If materials are modified as per discussion, learners with visual impairment may not face difficulties in accessing academic information but if materials are not modified they may face difficulties.

\section{Trained Teachers}

According to the social model it is believed that there must be adequate personnel preparation programs to train staff to provide specialized services which address the unique academic and nonacademic curriculum needs of students with visual impairment (Oliver, 2013). If learner with visual impairment are not taught by teachers who are trained in the field of special education particularly visual impairment they face academic problems. Learners with visual impairment academic needs in the areas of academic subjects will not be addressed because the teacher will not have the skill on how to handle a learner with visual impairment such as preparation of work into braille form, individual teaching, modification of curriculum, modification of teaching and learning materials. The learners with visual impairment will not acquire academic concepts and skills fully such as reading and writing skills. They may also acquire inadequate knowledge in all academic subjects. These are the academic difficulties which learner with visual impairment may face if they are not taught by a specially trained teacher in the teaching of learners with visual impairment.

\section{Financial Support}

The social model is on the understanding that the issue of inadequate funding to schools to a great extent hinders academic performance of learners with visual impairment in an inclusive school (Oliver, 2013). For instance inadequate funding may result in, unsuitable infrastructure, inadequate learning resources, inadequate trained teachers in special education.

Another aspect which this model looks at is economic barriers. According to Oliver (2013), Economic barrier such as poverty and unemployment contribute greatly to exclusion of children from accessing education. In line with the above statement, most parents of children with disabilities are unemployed and poor in that they struggle to feed and clothe them, meaning paying school fees is a luxury to them. In this case, learners with visual impairment are also affected in their academic work in that they have inadequate materials provided by their parents to help them 
perform well academically. All in all if there is lack of financial support it can affect learners with visual impairment in-terms of academic performance.

This social model fits well with the current research to be carried out which is the hurdles learner with visual impairment face academically because it will help the researcher in identifying and understand the hurdles that affect learners with visual impairment academically in inclusive schools. This is because the social model focuses on attitude, materials trained teachers and financial which will act as a framework for the study.

\subsubsection{Conceptual Framework}

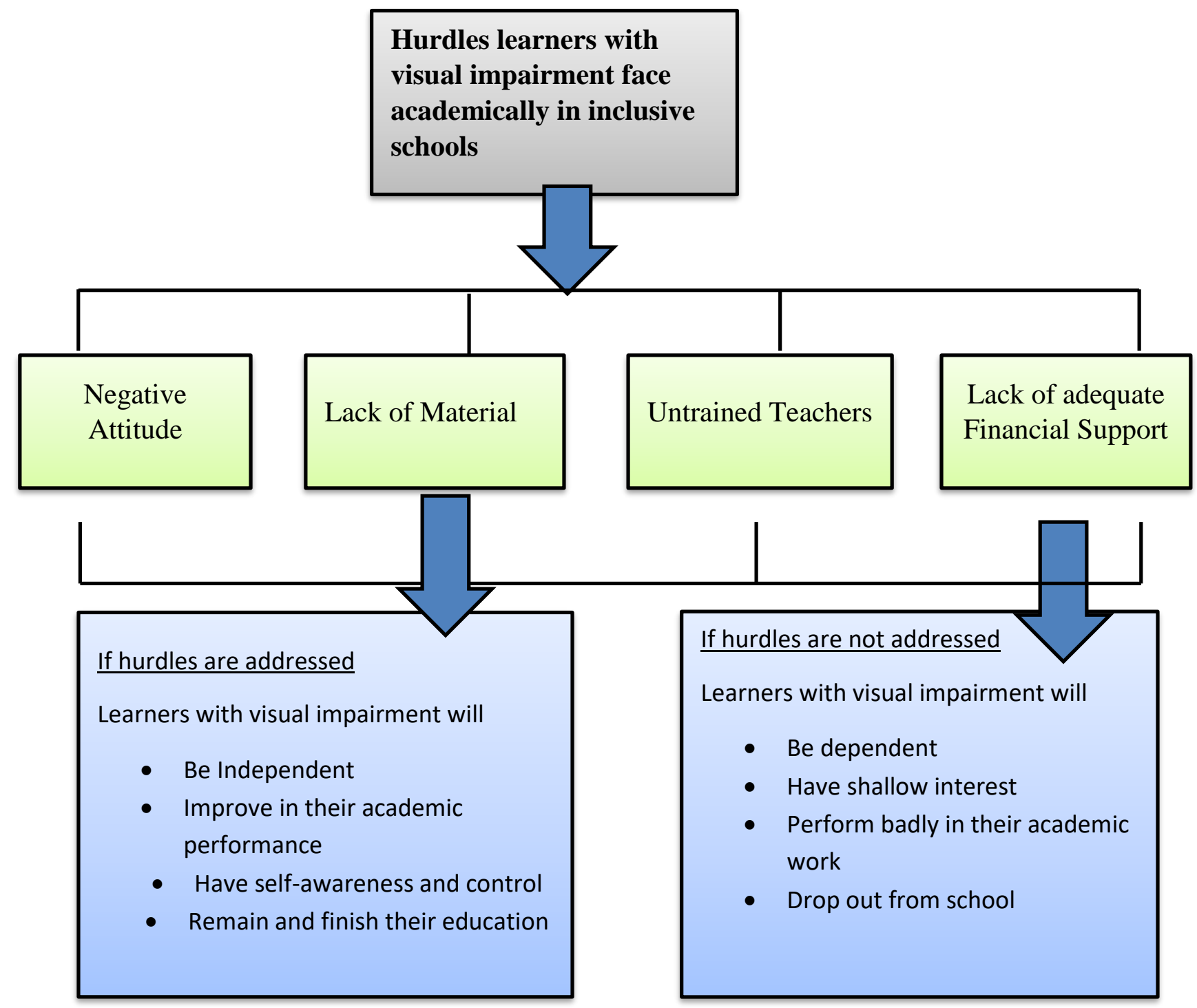

Figure 1.1: A diagrammatic representation conceptual framework of hurdles learners with visual Source: Researchers impairment face academically in inclusive schools 
This conceptual framework is on finding out and understanding the hurdles learners with visual impairment face academically. The arrows show a reflective path that the researcher will adopt throughout the research process. The framework starts with the exploring the meaning of hurdles learners with visual impairment face academically in inclusive school. Then this will be followed by explaining the four areas in which learners with visual impairment experience hurdles and these are attitude, materials, trained teachers and financial support. Thereafter, the framework end with the benefits which learners with visual impairment can benefit academically if the four areas in which they experience hurdles are addressed as well as the negative outcome if the four areas are not addressed.

\section{Hurdles Learners with Visual Impairment Face Academically}

A hurdle is a problem, difficulty, or part of a process that may prevent a person from achieving something. In this ongoing research, these are the problems or difficulties which learners with visual impairment may face academically or which can even make these learners not perform well in their academic work. Some of the hurdles these learners with visual impairment experience include negative attitude, lack of materials, untrained teachers and lack of adequate financial support. According to hawker (2015) attitude is a way of thinking, feeling or acting toward a person, thing or a situation. Educational materials are a subset of the book, games, internet and software among others. Trained teacher refer to qualified personnel with skills and knowledge needed to be imparted in a learner whilst financial support is a reserve supply that can be drawn upon when needed.

\section{Negative Attitude}

Teachers and learners attitude contribute to academic performance of learners with visual impairment in an inclusive school. Teachers are major social agents during the teaching and learning process of the learners with visual impairment. Teacher's general characteristics and role can either have negative or positive impact on a child (Luthans, 1989). For example a teacher who has a negative attitude will have negative views about teaching and interest on lessons, marking and guiding learners on hands -on experience. Learners who are not visually impaired may also contribute to poor performance of learners with visual impairment. For example, learners with visual impairment may be rejected during the group work activities and sometimes may not be given a helping hand by their sighted peers in terms of reading for them when the teacher give them work in printed materials. So the teacher should treat all learners equally in an inclusive school and giving them a warm and cheerful guidance and counseling. Otherwise, failure to which, learners with visual impairment might have problems in their academic performance.

\section{Lack of Material}

Materials are resources that are significant determinacy for effective learning. These materials for a learner with visual impairment include adequate items such as tactile and embossed materials which are relevant and readily available, and user friendly. Lack of resource materials may also mean that the learners with visual impairment becomes mere recipient of information because they do not have the opportunity to interact with the environment or learning by discovery approach and this has negative impact on learners with visual impairment. According to Habulezi and Phasha (2012) learners with visual impairment also need modified material to support them which may require more time to modify. For example, reading materials in larger print or font or in bolder colors for learners who are partially sighted is required in order to support them in their 
education. So providing both a print and a digital copy can be useful as this can be further adapted by the learners to suit, if needed. The use of wider range of Braille materials, audio-visual resources, and tactile pictures and diagrams can help these learners who are blind in their academic work.

\section{Untrained Teachers}

Untrained teaching is another area which contributes to hurdles leaners with visual impairment face in an inclusive school. According to Lamichhane (2017) instructions must be thoroughly prepared and provided by qualified personnel to teach learner with visual impairment. One of the qualifications which teachers must have is a foundation in regular education, including methodology in teaching academic subjects and skills such as reading, mathematics, and other areas of subject matter. Secondly the teacher must learn the techniques for curriculum adaptation, adapted teaching methodology and materials for learner with visual impairment. In addition, Ndhlovu (2008) mentioned that the teacher should know how to assess skills and deliver instructions in the specialized areas of independent living skills, social skills, career education, and specific areas of academics to learners with visual impairment. By doing so learners with visual impairment will be able to learn, acquire education and be independent.

\section{Lack of Adequate Financial Support}

According to Oliver (2013) inadequate funding was mentioned to be one of the challenges learners with disabilities face. In this case inadequate financial support from parents and other stake holders tend to hinder academic performance of learners with visual impairment in an inclusive school. If learners with visual impairment are provided with finances they may have access to some expensive equipment and materials which may help them academically. By overcoming this hurdle, the academic performance of learners with visual impairment may greatly improve.

\section{Conclusion}

Based on the discussion, the paper concludes that the social model and conceptual framework of hurdles learners with visual impairment face academically in inclusive schools can be used in identifying hurdles affecting learners with visual impairment in inclusive schools in Zambia. It involves aspects which includes; attitude, materials, trained teachers and financial support. Thus the aspect of attitude will be a guide in identifying how teachers and learners attitude contribute to academic performance of learners with visual impairment in an inclusive school these learners. The aspect material will be a guide in identifying materials used by learners with visual impairment during their time of learning. Furthermore, the aspect of trained teachers will be a guide in identifying if teachers have what it takes to handle these learners adequately. Finally, the aspect of financial support will be a guide in identifying if there will be inadequate financial support from parents and other stake holders for these learners.

\section{References}

[1] Angesa, L (2014). Challenges faced by learners with visual impairment in inclusive settings in Trans-nzoia couty Kenya Journal of Education and Practice. 5 (29) pp 185-192.

[2] Habulezi,J. and Phasia T.N (2012). Provision of learning support to learners with visual impairment in Botswana: a case study. Journal Social and Behavioural sciences 69 pp1555-1561.

[3] Hawker (2015). Little 0xford English dictionary. India: Oxford University. 
[4] Korir B.C (2015). Challenges encountered by students with visual impairment and teachers in integrated school environment: a case of integrated secondary schools in kericho district, ainomoi division, Kenya. International Journal of Education, Learning and Development 3 (8) pp28-40.

[5] Lamichhane, K (2017). Teaching students with visual impairment in an inclusive educational setting: a case study from Nepal. International journal of inclusive education. 21(1) pp 1-13.

[6] Leandro Luque, Leonidas O Brandao, Elisabeti Kira, Anarosa ,A.F. Brandao (2018). On the inclusion of learners with visual impairment in computing education programs in brazil; practices of educators and perceptions of visually impaired learners. Brazil.

[7] Journal of the Brazilian computer society.

[8] Oliver, M. (2013). Social model of disability thirty years on disability and society.

[9] Basingstoke: MacMillan.

[10] Ministry of Education (1996). Educating our future; national policy on education. Lusaka:

[11] Zambia educational publishing house.

[12] Ndhlovu, D. (2008). Challenges faced by pupils with disabilities in accessing education in inclusive schools in zambia. Lusaka: UNZA Press

[13] Sahasrabudhe, S. and Palvia, P. (2013). Academic challenges of blind students and their mitigation. Chikago: Illinois.

*Corresponding author.

E-mail address: nthamakap@gmail.com / anniependa@gmail.com 